\title{
PARA ALÉM DO LAZER: \\ A UTILIZAÇÃO DO FILME COMO RECURSO DIDÁTICO EM SALA

\author{
DE AULA
}

\author{
BEYOND CULTURE: \\ THE USE OF FILM AS A TEACHING RESOURCE IN THE CLASSROOM
}

Aline Apolinário Furtunato

Cinthia Torres Aranha ${ }^{1}$

\begin{abstract}
RESUMO: Pretende-se apresentar neste artigo um trabalho desenvolvido com base na ideia de aulas-oficinas (BARCA, 2004). Trabalhamos com estudo da História através das fontes em uma abordagem diferenciada do conteúdo tendo como fonte histórica o filme "A Múmia". Tendo em vista que a utilização do cinema como documento histórico vem sendo utilizada pelo historiador na construção do conhecimento histórico, pretende-se discutir os cuidados com a utilização desse recurso didático como documento no ensino de História, por exemplo, sobre o mundo antigo e a importância em distinguir ficção de "realidade" histórica. Através do filme buscou-se trabalhar as questões concernentes ao duo "realidade"/ficção, as visões contemporâneas estereotipadas acerca de outras sociedades do passado e abordar os costumes da sociedade egípcia antiga a partir dos vestígios materiais.
\end{abstract}

Palavras-chave: Cinema. Ensino de história. Sociedade egípcia. Conhecimento histórico.

\begin{abstract}
It is intended to present in this article a work based on the idea of Aula-Oficina (BARCA, 2004.) We work with the study of history through the fonts in a differentiated approach as a source of content and historical film "The Mummy." Considering that the use of film as a historical document has been used by the historian in the construction of historical knowledge, we intend to discuss care with the use of this document as a teaching resource in the teaching of history, for example, about the ancient world and the importance distinguishing fiction of "reality" historic. The theme used in classroom-workshop was "The Egyptian Society" and through the film we tried to work through the issues concerning the duo "reality"/fiction, the contemporary stereotypical views about other societies of the past and address customs of ancient Egyptian society from material traces.
\end{abstract}

Keywords: Cinema. History teaching. Egyptian society. Historical knowledge.

${ }^{1}$ Graduandas do curso de História da Universidade Estadual de Londrina. Bolsistas do Projeto PIBID. 


\section{Introdução}

A utilização de filmes em sala de aula vem sendo aplicada de forma a proporcionar um intervalo recreativo ou como um recurso de premiação pela cooperação dos alunos, conseqüentemente, o filme não costuma ser visto como uma fonte passível de ser estudada e analisada na aula de História.

Como tarefa do projeto PIBID (Programa Institucional de Bolsa de Iniciação à Docência) procuramos trabalhar, através do conceito de aulaoficina (BARCA, 2004), o filme "A Múmia"2 no Colégio Estadual Tsuru Oguido em Londrina, Paraná, no $6^{\circ}$ Ano B, de forma a analisar o filme como uma fonte histórica. Nesta análise, demos enfoque a quatro pontos principais: 1) dos cuidados com a utilização de filmes como recurso didático em sala de aula; 2) Estereótipos criados a partir de filmes "históricos" especialmente sobre a antiguidade; 3) A dualidade entre os conceitos de ficção x "realidade" histórica (MAGALHÃES; ALFACE, 2011); e 4) Procuramos analisar junto aos alunos os costumes e organização da sociedade egípcia antiga através de vestígios materiais representados no filme.

O trabalho foi desenvolvido a partir de um questionário de conhecimentos prévios. Com base nas respostas iniciamos o processo de análise com os alunos tendo o filme como fonte histórica.

\section{O desenvolvimento da aula-oficina}

A tarefa desenvolvida no $6^{\circ}$ Ano B do Colégio Estadual Tsuru Oguido, em Londrina-Paraná, pelo PIBID, teve como base o conceito de aula-oficina proposto por Isabel Barca, onde o professor assume seu papel de investigador social e entra em contato com o conhecimento que o aluno traz

2 Filme "A Múmia, 1999. Direção; Stephen Sommers. Com; Brendan Fraser, Rachel Weisz, John Hannah. Gênero; Aventura, Fantasia. Nacionalidade, EUA. 
previamente e se utiliza dele para desenvolver a aula através do trabalho com documentos, contextualizando-as em seu próprio espaço e tempo e partindo daí para uma compreensão da relação do passado longínquo, seu presente e a ligação com futuro.

Neste modelo, o aluno é efetivamente visto como um dos agentes do seu próprio conhecimento, as atividades das aulas, diversificadas e intelectualmente desafiadoras, são realizadas por estes e os produtos daí resultantes são integrados na avaliação. (BARCA, 2004, p. 132).

O conceito de documento traz implícita, no presente artigo, a sua utilização como fonte, tratando-se, portanto, de um indício de situações vividas no passado e passíveis de análise pelo historiador (CAINELLI; SCHMIDT, 2009), dessa forma, escolhemos o filme como fonte, recortandoo em algumas partes previamente selecionadas. O tema geral a ser abordado pela aula-oficina foi o "Antigo Egito" e escolhemos o filme "A Múmia" lançado em 1999. Escolhemos este filme porque acreditamos que ele apresenta determinadas características que contribuem para a criação de um imaginário popular a respeito do Antigo Egito e a análise destas características foram um dos pontos centrais abordados na aula-oficina. Outro motivo que levamos em conta na escolha é sua apresentação com certa freqüência na televisão aberta sendo assim de fácil reconhecimento pelos alunos.

Foi tomado como ponto de partida para o desenvolvimento do trabalho, o questionário de conhecimento prévio. As perguntas desempenharam o papel de observar o que o aluno entende por História; elucidar a relação entre aluno e fonte (especificamente, no caso, o filme); e por fim, duas questões direcionadas ao conteúdo substantivo a ser trabalhado, a sociedade egípcia antiga. 


\section{Dos cuidados com a utilização de filmes como recurso didático em sala de aula.}

Tendo em vista a proposta de aula-oficina (Barca, 2004), buscamos na utilização de filme como fonte histórica, uma alternativa para desconstruir a visão dos alunos sobre esse tipo de fonte. Em algumas observações das aulas em colégios estaduais e em contatos que tivemos com alguns alunos da rede pública, pudemos perceber a utilização desse artefato cultural feito pelos professores em sala de aula como um intervalo entre as matérias, ou apenas como um reforço da representação "verdadeira" do passado.

Levando em consideração essa situação recorrente da má utilização de filmes pelos professores em sala de aula, pode-se considerar que:

Muitas vezes, os professores, por uma série de fatores como ausência de recursos, quantidade excessiva de aulas, falta de motivação, comodidade, dentre outros empecilhos, prendemse ao livro didático e a aulas expositivas, com o uso exclusivo do quadro-negro e do giz. Noutras palavras, sentem-se despreparados para utilizar recursos que fogem a seus domínios específicos. (GUERRA; DINIZ, 2007, p. 130).

Buscamos na utilização do filme "A Múmia" proporcionar uma outra imagem sobre o uso de filmes em sala de aula já que este recurso é usado de forma que não auxilia na aprendizagem histórica, mas atinge seu objetivo que é recrear, e sendo assim, acaba empobrecendo esse grande recurso didático. De fato, no decorrer da oficina pudemos perceber a dificuldade em desmistificar a idéia de "recreação" ligada à projeção de filmes para os alunos, que estão acostumados com esse método.

\footnotetext{
Através de um filme, pode ocorrer uma aproximação maior com os fatos/momentos passados. Muitas vezes, o que temos dificuldade de compreender e/ou visualizar lendo um texto se torna mais claro quando assistimos a uma produção cinematográfica. Podemos dizer com base em nossas experiências de docência, que por meio das imagens o diálogo com outras temporalidades se expressa com maior eloqüência, ou seja, os alunos percebem com maior clareza
} 
como se davam as relações em outros contextos. (GUERRA; DINIZ, 2007, p. 135).

Além de ser prazeroso trabalhar com filmes em sala de aula, nosso objetivo foi analisá-lo como fonte histórica, sendo função do professor historiador

utilizar linguagens diferenciadas com intuito de propiciar aos alunos um processo de aprendizagem mais interativo, prazeroso e que tenha algum significado para sua vida, dando-Ihes condições de se posicionarem criticamente frente a diversas questões e aos problemas que os cercam (GUERRA; DINIZ, 2007, p. 129).

Procuramos então, apresentar em um primeiro momento o filme para os alunos, falando do roteiro, diretor, atores etc. Em seguida, passamos alguns trechos previamente selecionados do filme para mostrar aos alunos a representação que se tem na contemporaneidade a respeito do Antigo Egito, sendo observado no conhecimento prévio que poucos sabiam sobre o país, sua localização geográfica, sendo seus conhecimentos sobre o assunto aqueles difundidos em filmes, séries televisivas ou livros de aventura.

Após a visualização dos trechos, iniciamos uma leitura crítica das cenas apresentadas, tendo em vista que nenhum documento é neutro, principalmente tratando-se do cinema cuja função principal é o entretenimento e mesmo assim ele transmite ideologias próprias de sua época de produção.

[...] reforçamos que um filme equivale a uma montagem, uma (re)construção de um dado momento, de acordo com a ótica de seus produtores, o que não se limita somente ao posicionamento do diretor. Por isso, é fruto de uma seleção, pois na sua elaboração foram escolhidos quais aspectos seriam enfatizados, assim como outros que seriam ocultados. Em suma, uma representação de um dado fato ou contexto histórico, carregada de significados que podem estar explícitos ou não nas imagens que são dadas a ver. (GUERRA; DINIZ, 2007, p. 136).

Sendo assim, o professor historiador deve ter como objetivo "levar os alunos a questionarem e debaterem sobre o assunto, apontando seus posicionamentos e realizando uma análise crítica" (GUERRA; DINIZ, 2007). 
Para isso, utilizamos como contraponto fontes históricas próprias do período estudado. Ao apresentar uma cena do filme, mostrando uma múmia (Imhotep, o sacerdote) sendo amaldiçoada por ter cometido o pecado de se envolver com uma das mulheres favoritas do faraó, apresentamos como contraponto o "Livro dos Mortos", livro considerado um guia de boas condutas no qual o indivíduo iria ingressar na vida após a morte com base naquelas regras para conseguir passar pelo tribunal de Osíris e ser admitido no paraíso. Enfatizamos o papel do "Livro dos Mortos" como guia espiritual em uma sociedade que não diferenciava aspectos políticos, sociais ou culturais das práticas religiosas e seu valor como fonte histórica a ser analisada para a compreensão das formas de organização daquele povo.

Pudemos perceber nesse processo de análise do filme que boa parte dos alunos conseguiu construir uma linha de pensamento crítico sobre as cenas e começaram a questionar outros filmes sobre o mesmo tema, outros se focaram no entretenimento que o cinema proporciona ao público espectador, deixando a análise de lado e absorvendo apenas a visão "recreativa" da aula-oficina. Cremos, entretanto, a despeito desses alunos que não desenvolveram um senso crítico a contento, que a longo prazo, o modelo de aula-oficina com a análise de fonte cinematográfica deve obter êxito.

\section{Estereótipos criados a partir de filmes "históricos" principalmente sobre a antiguidade.}

Uma das intenções ao trabalhar com o filme "A Múmia" foi justamente a questão dos estereótipos sobre o mundo antigo presentes no filme.

Vivemos em uma era de imagens. Saber interpretar signos visuais tornou-se mais que uma necessidade para os acadêmicos e profissionais do ensino, mas uma necessidade. E justamente, o cinema se tornou uma das ferramentas mais utilizadas pelos historiadores para efetuar seu trabalho tanto em sala de aula como em pesquisas [...] (LANGER, 2004, p. 01). 
Tratando-se de um filme de ficção como "A Múmia", a interpretação das representações da "realidade" de uma sociedade, costumes, cultura e práticas (ainda que permeadas por inferências míticas como a própria figura da múmia) é extremamente pertinente. Não podemos esquecer que a escolha de como essa "realidade" é representada tem sua fundamentação e significação no contexto social do período em que foi produzido (no século XX, ano de 1999, no caso do filme utilizado), sendo assim o filme recebe influencias, mesmo que inconscientes, dos padrões culturais embutidos no presente no qual foi produzido. Essas influências para Langer são chamadas de "schematta". Entre outras especificações para a "schematta", podemos encontrar os estereótipos, sendo eles, "representações de uma realidade social ou histórica, tomadas como verdadeiras, mas que constituem quase sempre em fantasias ou produtos da imaginação" (LANGER, 2004, p. 02).

Essas representações são freqüentemente encontradas nas fontes imagéticas do cinema, no qual, acabam contribuindo para um desenvolvimento de um imaginário popular sobre a História.

\begin{abstract}
Marc Ferro já atentava para a percepção do filme tanto como fonte e objeto imagético. Não se pode simplesmente contrapor as imagens cinematográficas com a tradição escrita. É necessário perceber 0 filme enquanto testemunho/documento, integrando-o ao contexto social em que a obra surge: autor, produção, público, regime político, etc. Mas um filme não é feito apenas de imagens, mas também de textos escritos (legendas), sons (falas gravadas e trilha sonora), formando então um conjunto de representações visuais e textos (no sentido semiótico) [...] (FERRO apud LANGER, 2004, p. 03).
\end{abstract}

Partindo dessas questões procuramos trabalhar com os alunos não apenas a história do filme e como são retratados os egípcios, mas também as influências recebidas pelo contexto no qual ele foi produzido. No período de produção do plano de aula, pudemos observar nas pesquisas realizadas sobre o filme, poucas críticas a sua produção. "A Múmia" como boa parte dos filmes ficcionais hollywoodianos pautados na História, é produzido com a intenção de divertir a platéia não tendo a responsabilidade 
de um historiador em chegar mais próximo do que poderia ter sido a sociedade do "Antigo Egito", e por não possuir essa responsabilidade, todo seu enredo acaba criando vários estereótipos sobre esses povos.

A partir dessas questões pertinentes, procuramos trabalhar com a metodologia proposta por Langer, em seu texto "Metodologia para análise de estereótipos em filmes históricos", produzindo um roteiro de análise em etapas junto aos alunos e abordando: 1) Crítica externa do filme, verificando se o filme foi baseado diretamente em alguma literatura, histórias em quadrinhos dentre outros, seu período de produção, custos e outros fatores, 2) Crítica interna com seu conteúdo objetivo e conteúdo implícito no qual os produtores queriam passar ao espectador, mas não de forma direta, podendo trabalhar na aula-oficina com os estereótipos, visão etnocêntrica sobre a sociedade egípcia, religião, 3) Comparação e análise de conteúdos, podendo trabalhar com a comparação do filme com o conhecimento histórico do período a partir das fontes históricas (LANGER, 2004).

Pudemos perceber que o processo de desconstrução de estereótipos em filmes junto ao aluno, longe de provocar uma "desilusão" com a indústria de divertimento que é o cinema, desperta o interesse que envolve a produção dos mesmos e a reflexão a respeito da própria sociedade em que vive. Com o auxílio do professor, a leitura crítica desses recursos imagéticos irá proporcionar o posicionamento crítico do aluno a respeito do mundo.

\section{A dualidade entre os conceitos "ficção" x "realidade histórica".}

Pudemos observar através das respostas nos questionários de conhecimento prévio que a concepção que se tem de "verdade" é a de que existe uma verdade suprema e que é possível encontra-la em filmes, livro didático ou através do professor. Achamos particularmente necessário trabalhar em um primeiro momento da aula-oficina essa questão de 
desconstrução da idéia de verdade, visto que uma visão positivista desta provoca a ausência de pensamento crítico e analítico.

Como foi dito anteriormente, ao passarmos um trecho do filme em que se apresenta a mumificação do sacerdote Imhotep, ainda vivo, para que pagasse pelo pecado de ter tocado na mulher do faraó (e a idéia do filme é o retorno dessa múmia com o intuito de reaver seu amor perdido e de se vingar de sua maldição trazendo as dez pragas do Egito), buscamos contrapor essa visão contemporânea mítica e fantasiosa com imagens do "Livro dos Mortos" onde mostra a religiosidade envolvida nos rituais de mumificação e como a sociedade egípcia se organizava sem que houvesse uma linha divisória entre práticas religiosas, políticas e sociais.

Através de imagens em Power Point do Livro dos Mortos, buscamos analisar junto aos alunos, a escolha dos realizadores do filme de determinados aspectos da cultura egípcia para empregar o significado desejado em um filme de aventura e diversão. A própria figura de Imhotep, a múmia, foi retirada de um contexto maior e colocada como peça central do filme. Há registros de uma personalidade histórica que viveu entre 2.655 a 2.600 a.C. e foi arquiteto, médico, sacerdote, mágico, escritor e primeiro ministro a serviço do faraó Djoser da Terceira Dinastia. A Imhotep é creditado a arquitetura da primeira grande pirâmide do Egito, a pirâmide de Sacara, com seis enormes degraus e que atinge aproximadamente 62 metros de altura. No filme, Imhotep está a serviço de Seti I que, segundo registros históricos viveu entre 1291 a.C. a 1278 a.C. aproximadamente.

A figura feminina causadora das desventuras do filme, Anck-SuNamun foi inspirada na esposa do faraó Tutankhamon, Ankhesenamon, e que viveram aproximadamente entre 1.300 a 1.324 a.C. A descoberta da tumba de Tutankhamon e Ankhesenamon foi uma das maiores descobertas arqueológicas do século XX. Foi encontrada mais especificamente em 1922, pelo inglês Howard Carter e se tornou famosa por estar intocada e sem vestígios de saque.

Esses dados arqueológicos foram apresentados aos alunos para deixar claro o descompromisso que existe no meio midiático e do lazer com 
os fatos apresentados nos documentos históricos e procuramos enfatizar o papel do historiador e do cidadão crítico frente às construções representativas contemporâneas a respeito de épocas passadas.

\section{Da análise dos costumes e organização da sociedade egípcia através de vestígios materiais representados no filme (pirâmides, câmaras mortuárias, corpos mumificados, escritos sagrados).}

Questionamos os alunos sobre o porquê da utilização de um filme de ficção na aula de história, já que esse modelo de filme não apresenta os fatos do passado como um historiador apresentaria, tendo o cuidado para não causar anacronismo, podendo chegar a uma hipótese sobre como seria o "Antigo Egito" e recebemos algumas respostas como "Para conhecer a paisagem" ou "Para ver o Egito". A partir dessas respostas buscamos utilizar o filme como um suporte para a representação de vestígios materiais famosos como as pirâmides de Gizé, câmaras mortuárias, vasos canopos e escritos sagrados (como o Livro dos Mortos). E partindo desses vestígios, analisar a organização de uma sociedade que tinha presente a certeza da "vida após a morte", como as ações em vida poderiam influenciar a jornada além túmulo e como esses aspectos influenciaram profundamente a organização da sociedade.

- Pirâmides - O primeiro vestígio material que trabalhamos foi a pirâmide. Utilizamos um documentário da BBC ("A Construção das Grandes Pirâmides"), onde apresenta os processos técnicos na sua construção, a mão-de-obra necessária e os preceitos religiosos envolvidos. Em power point colocamos imagens de pirâmides e os aposentos e modos de proteção contra saqueadores. Chamamos a atenção para alguns faraós que gastavam fortunas imensas e até mesmo a vida com a obsessão em construir pirâmides luxuosas

- Câmaras Mortuárias - No filme, o sacerdote amaldiçoado Imhotep é condenado ao "Hom-dai", um ritual onde o indivíduo era mumificado vivo e sobre seu corpo trancado no sarcófago colocavam-se besouros para lhe 
comer as carnes. O sarcófago era, então, sepultado sob os pés de Anúbis, o deus com a cabeça de chacal. Os alunos se mostraram curiosos do porque desse modo de enterrar o morto e não nas câmaras mortuárias. Utilizamos esses questionamentos como gancho para a análise das câmaras e dos próprios rituais de mumificação.

Através do "Livro dos Mortos" analisamos junto a eles as imagens com os processos ritualísticos que garantiriam ao morto e sua família o conforto da viagem ao além. Ficaram particularmente curiosos com os artefatos encontrados nas câmaras (tabuleiros de xadrez, jogos diversos, mobília, comida).

- As múmias - Começamos a análise sobre as múmias traçando um paralelo com os costumes de diversas religiões, incluindo a cristã, onde a preocupação com o que acontece posteriormente à morte biológica permanece como uma constante na natureza humana. A obsessão com a imortalidade e o medo do desconhecido sempre motivou as sociedades a buscarem explicações coerentes e coesas a esse respeito (SENTINELLA, 2008). Os rituais de mumificação tratam dessa preocupação.

\begin{abstract}
A crença nesse mais além foi evoluindo, ao mesmo tempo que foi surgindo uma série de ritos funerários, a princípio toscos e elementares, mas que com o tempo se transformaram em representações cada vez mais complexas e ricas em detalhes. Desde os jantares rituais de restos humanos ou de cinzas dos mortos, que ainda hoje são praticados por algumas tribos, até o embalsamamento mais elaborado realizado há 8.000 anos no deserto da Arica, norte do Chile, ou as perfeitas mumificações realizadas no antigo Egito. Quanto mais complexas tem sido as crenças sobre essa existência após a morte, mais complicados tem sido os rituais praticados. (SENTINELLA, 2008, p. 16)
\end{abstract}

A partir dos rituais de mumificação apresentados em alguns trechos do filme e de imagens do "Livro dos Mortos", procuramos analisar junto aos alunos as permanências sentidas nas concepções religiosas de vida após a morte nas sociedades como uma característica inerente ao ser humano.

- Escritos Sagrados - Um dos recortes que fizemos no filme apresenta o papel essencial que "O Livro dos Mortos" tem na ressurreição 
da múmia. Procuramos então uma imagem do livro onde mostra o tribunal de Osíris, aonde Anúbis conduz o morto para ser feita a pesagem da alma contra uma pena, se a alma for mais pesada que a pena, o morto é lançado no fogo ou na água fervente. A análise proposta foi a de pensar "O Livro dos Mortos" como um livro de regras para a vida após a morte e que, influenciava diretamente a vida terrena e a conduta do indivíduo de modo a ser enviado ao Paraíso de felicidade e não aos infortúnios.

\section{Considerações finais}

Como trabalho de conclusão da aula-oficina, pedimos aos alunos que desenvolvessem uma narrativa a respeito da análise dos trechos do filme, dos documentos apresentados e produzissem um desenho apontando qual tema da aula mais gostaram. Apresentaremos aqui algumas respostas de quatro alunos, dois que desenvolveram um conhecimento substantivo e relacionaram o filme aos documentos apresentados na aula-oficina (representados aqui como A1 e A2) e os outros dois (representados como B1 e B2) que apenas falaram sobre o filme sem uma construção de um conhecimento substantivo.

Aluno A1: No Egito existiram vários faraós e cada um deles tinha uma tumba para quando ele morrer ser enterrado lá.

Quando um faraó é enterrado todos os pertences dele são enterrados juntos a ele.

Existia um faraó que queria ter a maior pirâmide de todas e ele construiu uma pirâmide e quase gastou todo o dinheiro da cidade. (sic)

Aluno A2: No Egito a cultura é muito diferente da cultura brasileira como por exemplo: eles mumificam os faraós ao invés deles fazerem cemitérios para os defuntos eles fazem pirâmides gigantes e também eles colocam ouros e riquezas do faraó enterradas junto com eles. (sic)

Aluno B1: A muitos anos atrás a.c. o Egito passou por muitas mudança o deus Anúbis comandava no Egito ele tinha cabeça de cachorro e ele guardava um livro dos mortos. 
Esse rei tinha aliado que também tinha cabeça de cachorro e uns dos aliados não obedeceu as regras e como rainha estava traindo seu rei. Se matou e o aliado foi castigado.( Sic)

Aluno B2: A parte legal. Foi quando o Inohotep foi enterrado vivo na tumba com os bichos comendo ele. Quando o Rick foi dando tiro nas pessoas quando apareceu a cara do faraó foi muito legal quando Ancksunamun tentou se matar porque ela preferia morrer dando uma facada nela mesmo do que morrer comida por bichos. (sic)

Utilizando a proposta de aula-oficina de Isabel Barca, pudemos perceber que buscar a autonomia do aluno levando em conta seus conhecimentos prévios e lhe proporcionando um método de aula no qual ele é agente de seu próprio conhecimento, contribui para que aulas com utilização de filmes como fontes não sejam apenas uma "recreação". Esse processo faz com que as aulas sejam mais dinâmicas e a participação do aluno seja bem maior. De fato, muitos alunos se prendem ainda a idéia de "diversão", sem uma construção de um pensamento histórico crítico ao assistir um filme ou trechos selecionados. Esse dado pode ser observado no gráfico abaixo, no qual boa porcentagem dos alunos não conseguiu chegar a um conhecimento substantivo sobre a aula-oficina (Barca, 2004), e pensamos que se deve ao tempo curto em que desenvolvemos a aulaoficina sendo esta uma atividade possível de ser desenvolvida com êxito pelo professor regular. Os alunos que conseguiram alcançar o objetivo pretendido foram poucos, porem, em suas narrativas apresentaram bem 0 conteúdo substantivo sobre a história do Egito. É preciso salientar a necessidade de um maior esforço por parte dos professores para que a utilização de linguagens diferenciadas em sala de aula seja algo substantivo para os alunos e com maior interação.

O cinema como fonte histórica

pode, portanto, fazer parte do elenco das fontes da História, pelo que representa como criação e como manifestação do imaginário. Seja por envolver um complexo processo econômico produtivo, como pela quantidade de informações que contém e que nem sempre correspondem exatamente 
aos objetivos de seus autores, ou pelo valor enquanto testemunho de uma sociedade e de uma época. (MEIRELLES, 2004, p. 82)

E pensá-lo como recurso didático, "conseguir analisar produções cinematográficas, desconstituir seus estereótipos e criar um referencial crítico nos estudantes é uma meta importante para qualquer educador" (Langer, 2004). Meta importante, possível e necessária para uma melhora no ensino e uma maior compreensão dos diversos recursos disponíveis para ser desfrutados em sala de aula.

\section{Referências Bibliográficas:}

BARCA, I. Aula Oficina: do Projeto à Avaliação. In: BARCA, I. Para uma educação de qualidade: Atas da Quarta Jornada de Educação Histórica. Braga, Centro de Investigação em Educação (CIED)/ Instituto de Educação e Psicologia, Universidade do Minho, 2004, p. 131-144.

CAINELLI, M; SCHMIDT, M. A. Ensinar História. Editora Scipione: São Paulo, 2009.

GRIMBERG, C. A Aurora da Civilização. v. 1. Editora Azul: Chile, 1989. O Império das Pirâmides Vol. 2. Editora Azul: Chile, 1989.

GUERRA, F. de P.; DINIZ, L. M. V. A incorporação de outras linguagens ao ensino de história. História \& Ensino. n. 13, 2007.

LANGER, J. Metodologia para análise de estereótipos em filmes históricos. Revista História Hoje. São Paulo, n. 5, 2004.

MAGALHÃES, O.; ALFACE, H. O Cinema como recurso pedagógico na aula de História. In: CAINELLI, M.; SCHMIDT, M. A. (Org.). Educação Histórica: Teoria e Pesquisa. Editora Unijuí: Rio Grande do Sul, 2011. p. 249-267

MEIRELLES, W. R. O cinema na história. O uso do filme como recurso didático no ensino de história. História \& Ensino. v. 10, 2004.

MUZY, S. R. F. A Criação das Bases do monoteísmo pelo faraó Akhenaton (1353-1336 AEC.) e sua implicações sociais no Antigo Egito. In: SELVATICI, M.; CERQUEIRA, F. V. (Org.). Religião e Poder do Mundo Antigo ao Moderno: Ensaios Acadêmicos. LEPAARQ/UFPEL: Pelotas, 2009.

SENTINELLA, D. E. O Enigma das Múmias. Novo Século: São Paulo, 2008. SIMÃO, A. C. G. L. L. A Importância da evidência histórica na construção do conhecimento histórico. In: CAINELLI, M.; SCHMIDT, M. A. (Org.). Educação 
Histórica: Teoria e Pesquisa. Editora Unijuí: Rio Grande do Sul, 2011. pp: 143-166.

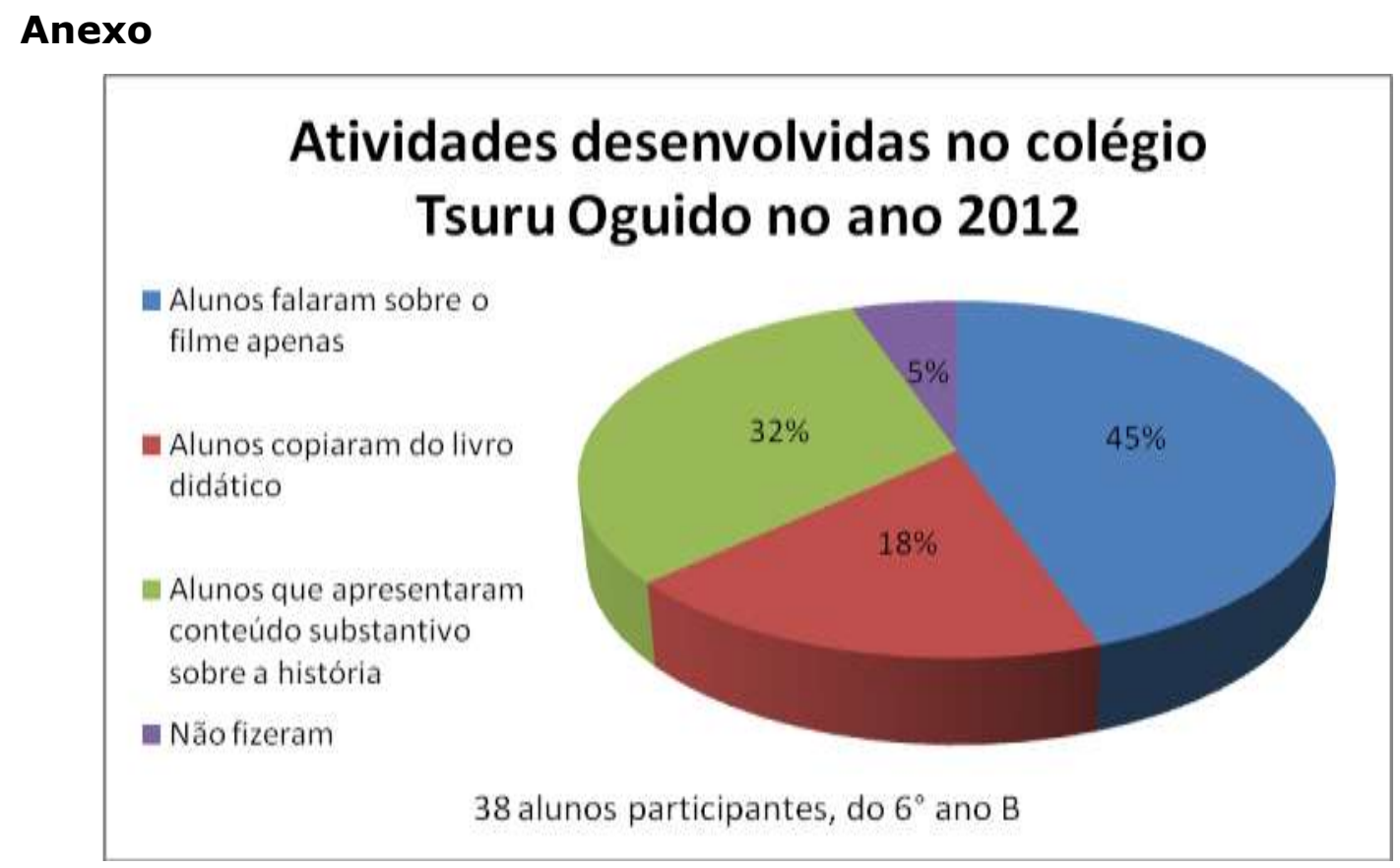

Figura 1: Atividade desenvolvida na proposta de aula-oficina (Barca, 2004). 